\title{
Feedback effects of steroids and gonatrophin control in adult rats with streptozotocin-induced diabetes mellitus
}

\author{
R. A. Blades, K. R. Bryant and S. A. Whitehead \\ Department of Physiology, St. George's Hospital Medical School, London, UK
}

\begin{abstract}
Summary. The effects of long- and short-term streptozotocininduced diabetes mellitus on the control of gonadotrophin secretion have been investigated in adult intact rats. A high dose of streptozotocin $(80 \mathrm{mg} / \mathrm{kg})$, administered intraperitoneally 3 days before experimentation, inhibited ovulation and reduced the pituitary luteinizing hormone response to luteinizing hormone releasing hormone in proestrous rats. A lower dose $(40 \mathrm{mg} / \mathrm{kg})$ did not inhibit ovulation but abolished the luteinizing hormone releasing hormone-priming effect on the pituitary which normally occurs on proestrus, prior to ovulation. Oestrous cyclicity was lost when diabetes was induced for 14 or 56 days, but there was no effect on pituitary responsiveness to luteinizing hormone-releasing hormone compared with control animals. Similar observations were made with rats placed on a food-restricted diet. In all experiments there was no difference between diabetic and control animals in the pituitary luteinizing hormone content, the hypothalamic con-
\end{abstract}

tent of luteinizing hormone-releasing hormone or the ovarian weights. Ovariectomized rats treated with streptozotocin $(40 \mathrm{mg} / \mathrm{kg}$ ) were used to investigate the effects of diabetes on steroid feedback mechanisms. There was an attenuated luteinizing hormone response to ovariectomy in diabetic compared with control animals, and an impaired positive feedback effect of progesterone in oestrogen-primed animals. The results show that streptozotocin-induced diabetes mellitus inhibits feedback action of gonadal steroids and this could account for both the loss of oestrous cyclicity and the reduced pituitary sensitivity to luteinizing hormone-releasing hormone.

Key words: Streptozotocin, diabetes mellitus, fertility, luteinizing hormone, luteinizing hormone - releasing hormone, steroid feedback, body weight.
It is well known that diabetic patients show an increased incidence of infertility [1], but the mechanisms by which diabetes mellitus impairs reproductive functions are poorly understood. Drug-induced diabetes mellitus in the female rat has frequently been used as an experimental model to investigate the causes of this association, since both alloxan- and streptozotocin-induced diabetes result in ovulatory failure $[2,3]$. A reduced sensitivity of the pituitary gonadotrophs to luteinizing hormone-releasing hormone (LHRH) has been observed in diabetic rats [4] but this could be attributed to an impairment of LHRH secretion since the releasing hormone regulates its own pituitary receptors [5]. Indeed, the available evidence strongly indicates that diabetes inhibits the hypothalamic regulation of gonadotrophin secretion, and this could involve a failure in the feedback action of gonadal steroids. However, a direct effect of diabetes on the pituitary gland or on the ovary cannot be excluded.

The majority of studies have been carried out on the immature animal in which ovulation is stimulated by the administration of pregnant mare's serum gonadotrophin. This particular animal model has some disadvantages since it precludes the changes in the hypothalamic-pituitary axis which occur at the time of puberty, and the observed ovulation is not a spontaneously occurring event as in the adult animal. Furthermore the endocrine effects of diabetes mellitus on reproductive functions have generally been carried out within a relatively short period after alloxan or streptozotocin (STZ) treatment, typically 4-6 days, and little attention has been paid to the severity of the experimental diabetes.

There were several objectives to the present study. Firstly, to ascertain whether the effect of STZ-induced diabetes on ovulation and pituitary responsiveness were similar in adult compared with immature animals, and to investigate the relationship between the severity of the diabetes and the impairment of gonadotrophin secretion. Secondly, to compare the effects of short term ( 3 days) and chronic (14 or 56 days) diabetes on oestrous cyclicity and pituitary responsiveness. Thirdly, to establish the contribution of weight loss in experimen- 
tally-induced diabetes, since weight loss in itself can cause anovulation and reduced pituitary responses similar to those observed prepubertally [6]. Finally, to determine whether steroid feedback action is impaired in diabetes by investigating the luteinizing hormone (LH) response after ovariectomy and the effect of gonadal steroid administration to the ovariectomized diabetic rat.

\section{Materials and methods}

\begin{abstract}
Animals
Adult female virgin Porton Wistar rats, weighing between $200-250 \mathrm{~g}$, were maintained under conditions of controlled lighting (lights on $06.00-18.00$ hours) and temperature $\left(20^{\circ} \mathrm{C}\right)$. Oestrous cyclicity was monitored by daily vaginal smears and all rats used in these studies had exhibited at least two regular 4-day oestrous cycles prior to treatment. Diabetes was induced by STZ ( 40 or $80 \mathrm{mg} / \mathrm{kg}$; Sigma, London, UK) administered intraperitoneally after a $24-\mathrm{h}$ fast. The drug was dissolved in citrate buffer $(100 \mathrm{mmol} / 1, \mathrm{pH} 4.5)$ immediately before injection; an equivalent volume of buffer alone was given to control animals. The next day glycosuria and ketonuria were measured semiquantitatively using Labstix (Miles Laboratories, Stoke Poges, Bucks, UK) and only those animals which were diagnosed as glycosuric (+ equals $14 \mathrm{mmol} / 1$ or above) were used in the experiments. Vaginal smears and body weight were recorded daily, and for the long-term diabetic experiments glycosuria and ketonuria monitored twice weekly. All rats had free access to food and water except for those animals in which the effects of body weight loss were being investigated. In this instance, food ( $41 \mathrm{~B}$ pellets) was restricted to $<10 \mathrm{~g} /$ day to achieve an approximate $10 \%$ reduction in body weight over a 14 -day period.
\end{abstract}

\section{Experimental methods}

On the day of experimentation, animals were decapitated between 10.30-11.00 hours and trunk blood collected for measurement of blood glucose and serum LH and prolactin concentrations. The pituitary gland was rapidly dissected and after removal of the neurointermediate lobe, half the gland was used for in vitro tests of $\mathrm{LH}$ responses to LHRH and the corresponding hemipituitary was placed on ice in $1 \mathrm{ml}$ Krebs Ringer Bicarbonate (KRB) and used for measurement of pituitary LH content. In those animals which were killed on the expected day of oestrus, ovulation was assessed by examination of the Fallopian tubes and extraction and counting of the released ova.

The LH was extracted from the hemipituitaries by immediate homogenization in $1 \mathrm{ml} \mathrm{KRB}$ and centrifugation ( $8000 \mathrm{~g}$ for $5 \mathrm{~min}$ ); the supernatant was stored at $-20^{\circ} \mathrm{C}$ and subsequently assayed for LH. The hypothalamic content of LHRH was extracted with an identical method, except in this instance the KRB contained bacitracin $(1 \mathrm{mmol} / 1$, Sigma). The blocks of hypothalamic tissue measured approximately $5 \times 4 \times 2 \mathrm{~mm}$, the weights varying between $28-35 \mathrm{mg}$. The optic chiasma and the mamillary bodies defined the rostral and caudal limits respectively and the median eminence was always included.

\section{Pituitary $L H$ responses to $L H R H$}

In vitro tests of pituitary responsiveness to pulses of LHRH were measured using a perifusion system which has been described previously in detail [7]. The glands were perifused with KRB, containing glucose $(2 \mathrm{~g} / \mathrm{l})$ and bovine serum albumin $(2.5 \mathrm{~g} / 1)$, at a rate of $0.2 \mathrm{ml} /$ min. The medium was gassed with $95 \% \mathrm{O}_{2} / 5 \% \mathrm{CO}_{2}$ and the perifusion chambers maintained at $37^{\circ} \mathrm{C}$ in a water bath. After an initial period of $2 \mathrm{~h}$, during which time the rate of basal $\mathrm{LH}$ release reaches a steady state, 10-min perfusate fractions were collected for a further $2 \mathrm{~h}$. Two 5-min pulses of $10 \mathrm{ng}$ synthetic LHRH/ml KRB (Cambridge
Research Biochemicals, Cambridge, UK) were delivered to the gland with an interval of $1 \mathrm{~h}$ between each pulse. Perfusate fractions were stored at $-20^{\circ} \mathrm{C}$ until assayed for $\mathrm{LH}$.

\section{Assays}

Blood glucose levels were measured using the glucose oxidase-Perid method (Boehringer Mannheim, Mannheim, FRG) and any experimental animal that did not have blood glucose levels $>9 \mathrm{mmol} / 1$ when measured by this method were excluded from analysis. LH and prolactin concentrations were measured by double-antibody radioimmunoassays $[8,9]$ using materials and protocol supplied by the $\mathrm{Na}$ tional Hormone and Pituitary Program (NHPP), Baltimore, Maryland, USA and are expressed in terms of NHPP rat LH-reference preparation (RP) 1 and prolactin-RP2. Inter- and intra-assay coefficients of variation were $10.2 \%$ and $9.4 \%$, respectively, for $\mathrm{LH}$ and $10.1 \%$ and $8.9 \%$ for prolactin. The sensitivities of the assays were $10 \mu \mathrm{g} / 1$ for $\mathrm{LH}$ and $1 \mu \mathrm{g} / 1$ for prolactin. The hypothalamic concentration of LHRH was measured by a single antibody radioimmunoassay [10] using synthetic LHRH (Cambridge Research Biochemicals). The antiserum to LHRH was a gift of Dr. H. M. Fraser (Medical Research Council, Unit of Reproductive Biology, Edinburgh, UK) and the sensitivity of the assay was $10 \mathrm{ng} / \mathrm{l}$; inter-and intra-assay variations were $10.7 \%$ and $7.0 \%$, respectively.

\section{Study design}

Experiment 1. Rats at different stages of the oestrous cycle were injected with either 40 or $80 \mathrm{mg} / \mathrm{kg} \mathrm{STZ}$ or citrate buffer at 12.00 hours. The following day their urine was tested for ketonuria and glycosuria. Vaginal smears were recorded daily. Three days after induction of diabetes, the animals were used for experimentation and for each animal pituitary LH responses to LHRH, serum LH and prolactin concentrations and pituitary LH and hypothalamic LHRH contents were measured. Ovulation was determined in the animals which were injected with STZ on dioestrous day 1 and killed on the next expected oestrus.

Experiment 2. Similar studies as described for Experiment 1 were carried out on animals in which diabetes had been induced either 2 or 8 weeks before experimentation. For these groups of animals only the lower dose of STZ ( $40 \mathrm{mg} / \mathrm{kg}$ ) was used to induce diabetes mellitus.

Experiment 3. Rats with regular 4-day oestrous cycles were given a restricted food diet for a mean period of 26 days. This period ensured that all animals tested had lost a minimum of $10 \%$ body weight since initiating the diet. The same measurements as those described for experiment 1 were made on the experimental and control groups of animals which received food ad libitum.

Experiment 4. Rats were injected with STZ $(40 \mathrm{mg} / \mathrm{kg})$ or diluent alone, and the next day (day 1) ovariectomized under ether anaesthesia. Blood samples $(0.5 \mathrm{ml})$ were taken between 12.00 and 12.30 hours by cardiac puncture under ether anaesthesia on days $1,4,5,6,7,8,11$, 13 and 15 from all rats, and body weights recorded at the same time. On day 15 , oestradiol benzoate $(80 \mu \mathrm{g} / \mathrm{kg}$ Sigma) dissolved in corn oil was injected subcutaneously at 12.00 hours. Three days later a further blood sample was taken prior to a subcutaneous injection of progesterone $(10 \mathrm{mg} / \mathrm{kg}$ Sigma) at 12.00 hours. At 17.00 and 18.00 hours two final blood samples were obtained. In a second group of animals, ovariectomies were performed 3 weeks prior to treatment with STZ $(40 \mathrm{mg} / \mathrm{kg})$ or vehicle alone. Thirty days later the rats were killed and similar measurements as those described for experiment 1 were made.

\section{Statistical analysis}

All data are expressed as mean \pm SEM. Statistical significance between the two groups were evaluated with an unpaired two-tailed Student's t-test, but when more than two groups were compared a oneway analysis of variance with Gabriel's test [11] was used since this particular test is suitable for multiple comparisons between unequal group sizes. The ovulation studies were analysed with a $\chi^{2}$ test. 


\section{Results}

Experiment 1. Effects of short-term diabetes on ovulation and pituitary responsiveness to $L H R H$

The animals were divided into two groups according to their vaginal smears on the day of experimentation. Group A were those animals which displayed oestrous or dioestrous vaginal smears, and group B had proestrous smears. This classification was made since there is a marked increase in pituitary responsiveness recorded on proestrus compared with other stages of the oestrous cycle. The effects of STZ ( 40 and $80 \mathrm{mg} / \mathrm{kg}$ ) in the two groups of animals on blood glucose levels, weight loss, plasma LH and prolactin concentrations, the pituitary LH content and the hypothalamic content of LHRH are shown in Table 1. All experimental animals had blood glucose concentrations $>9.5 \mathrm{mmol} / 1$ and the severity of hyperglycaemia was related to the dose of STZ, as was weight loss over a 3 -day period. Ketonuria ( $>$ $3.9 \mathrm{mmol} / \mathrm{l}$ ) was only detected in two out of the $28 \mathrm{dia}-$ betic rats investigated, and these animals had been treated with the high dose of STZ.

In group A (oestrous/dioestrous) animals there were no significant differences in pituitary $\mathrm{LH}$ responses to $5 \mathrm{~min}$ pulses of LHRH between the controls and rats treated with either the high or low dose of STZ (Fig. 1). In contrast, there was a marked impairment of the pituitary responses when diabetic rats were tested on proestrus. The increased LH response to the second pulse of LHRH observed in the control group was absent in rats treated with $40 \mathrm{mg} / \mathrm{kg} \mathrm{STZ}(p<0.05)$, while the $80 \mathrm{mg} / \mathrm{kg}$ dose significantly attenuated the LH responses to both pulses of LHRH ( $p<0.05$, Fig. 1). There were no significant differences between the circulation $\mathrm{LH}$ and prolactin concentrations in any of the animals tested, except in proestrous rats treated with STZ $(80 \mathrm{mg} / \mathrm{kg})$. These animals had significantly lower pro- lactin levels compared with either the controls or animals made diabetic with the lower dose of the drug (Table 1). The results of the ovulation studies are shown in Table 2. The low dose of STZ did not inhibit ovulation in any of the five diabetic animals tested, whereas ovulation was inhibited in all eight diabetic rats treated with the $80 \mathrm{mg} / \mathrm{kg}$ dose of the drug. Ketonuria was detected in four of these eight animals.

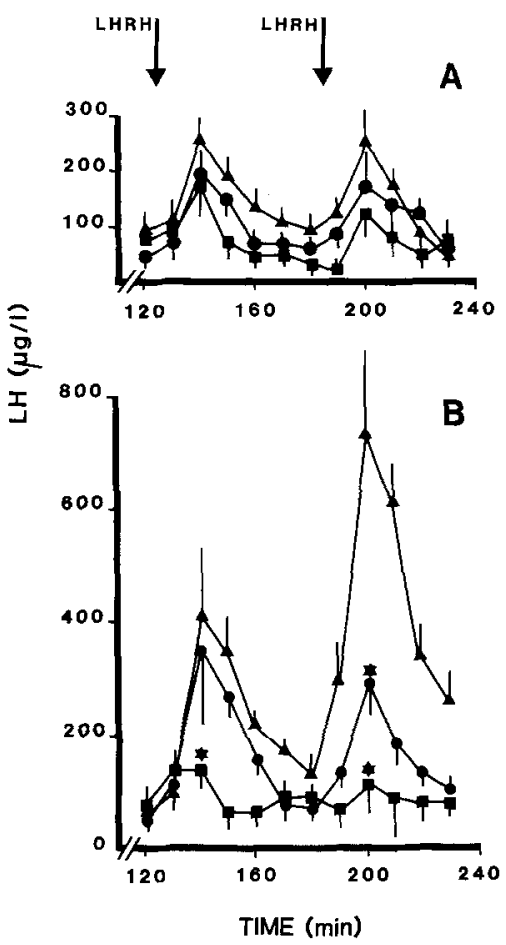

Fig. $1 \mathrm{~A}$ and B. Effects of 3-day STZ-induced diabetes on pituitary $\mathrm{LH}$ responses in vitro to two 5-min pulses of LHRH. A The responses observed from perfused pituitary glands of oestrous and diestrous rats and $\mathrm{B}$ the $\mathrm{LH}$ responses of pituitary glands of proestrous rats. $\square$ animals treated with STZ $(80 \mathrm{mg} / \mathrm{kg})(n=8) ;-\mathrm{STZ}(40 \mathrm{mg} / \mathrm{kg})$ $(n=8)=$ and $\Delta$ control rats treated with vehicle alone $(n=11)$ * $p<0.05$ (Gabriel's test)

Table 1. Effects of 3-day STZ-induced diabetes on body weight, LH and prolactin secretion and pituitary LH and hypothalamic LHRH contents measured in rats in oestrus/dioestrus and proestrus

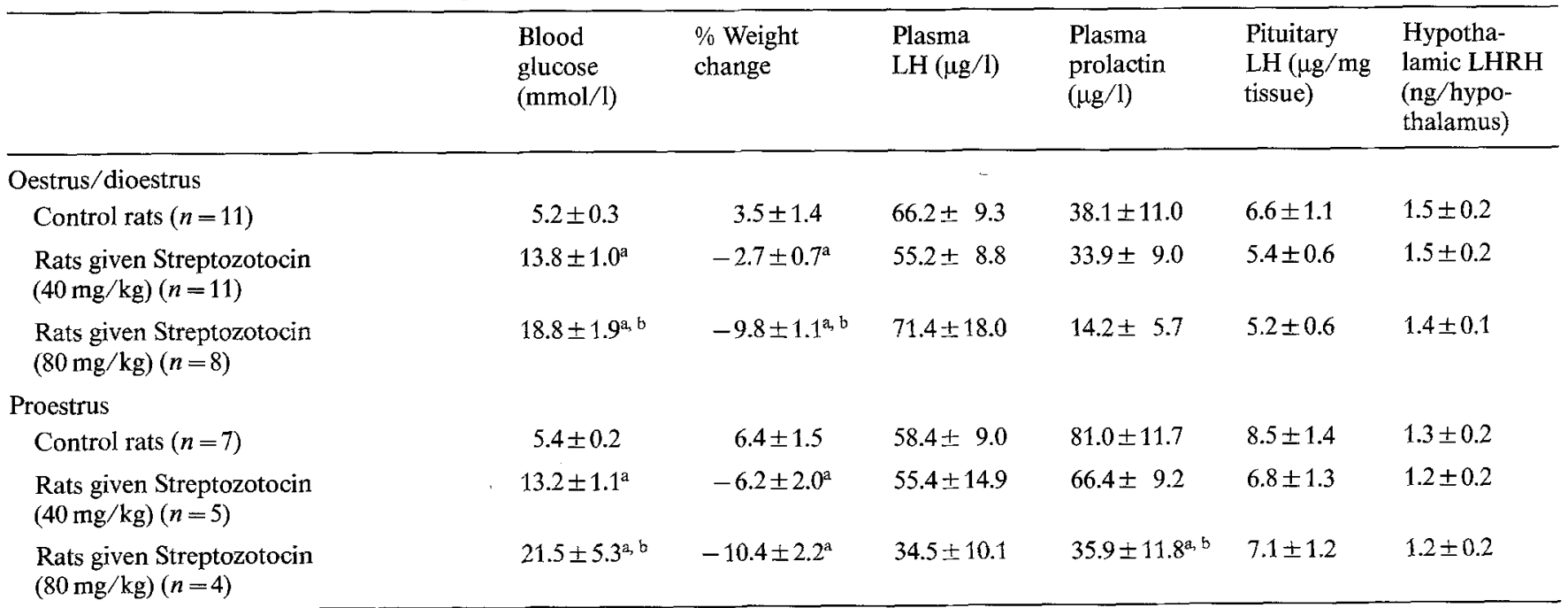


Table 2. Effects of STZ treatment of dioestrous rats on the occurrence of ovulation on the next expected oestrus

\begin{tabular}{|c|c|c|c|c|c|c|}
\hline & $\begin{array}{l}\text { Blood glucose } \\
(\mathrm{mmol} / \mathrm{l})\end{array}$ & $\begin{array}{l}\% \text { Weight } \\
\text { change }\end{array}$ & $\begin{array}{l}\text { No. rats } \\
\text { ovulating }\end{array}$ & $\begin{array}{l}\text { Mean no. } \\
\text { of ova }\end{array}$ & $\begin{array}{l}\text { Plasma LH } \\
(\mathrm{g} / \mathrm{l})\end{array}$ & $\begin{array}{l}\text { Plasma } \\
\text { prolactin }(g / 1)\end{array}$ \\
\hline Control rats $(n=9)$ & $4.9 \pm 0.3$ & $4.1 \pm 1.5$ & 8 & $10.7 \pm 0.8$ & $89.8 \pm 8.2$ & $17.9 \pm 4.5$ \\
\hline $\begin{array}{l}\text { Rats given streptozotocin } \\
\quad(80 \mathrm{mg} / \mathrm{kg})(n=8)\end{array}$ & $17.7 \pm 1.8^{\mathrm{b}, \mathrm{d}}$ & $-14.5 \pm 2.4^{a}$ & $0^{\mathrm{c}, \mathrm{d}}$ & - & $76.4 \pm 19.6$ & $39.7 \pm 14.1$ \\
\hline
\end{tabular}

Values expressed as mean $\pm \mathrm{SEM}$; number of animals given in parentheses. ${ }^{\mathrm{a}} p<0.05,{ }^{\mathrm{b}} p<0.01$ and ${ }^{\mathrm{c}} p<0.001$ compared with controls (Gabriel's Test); ${ }^{\mathrm{d}} p<0.05$ significant difference between the two treated groups (Student's t-test or $\chi^{2}$ )

Table 3. Effects of STZ-induced diabetes and food restriction on body weight, LH and prolactin secretion, pituitary LH content and ovarian weights in three groups of rats

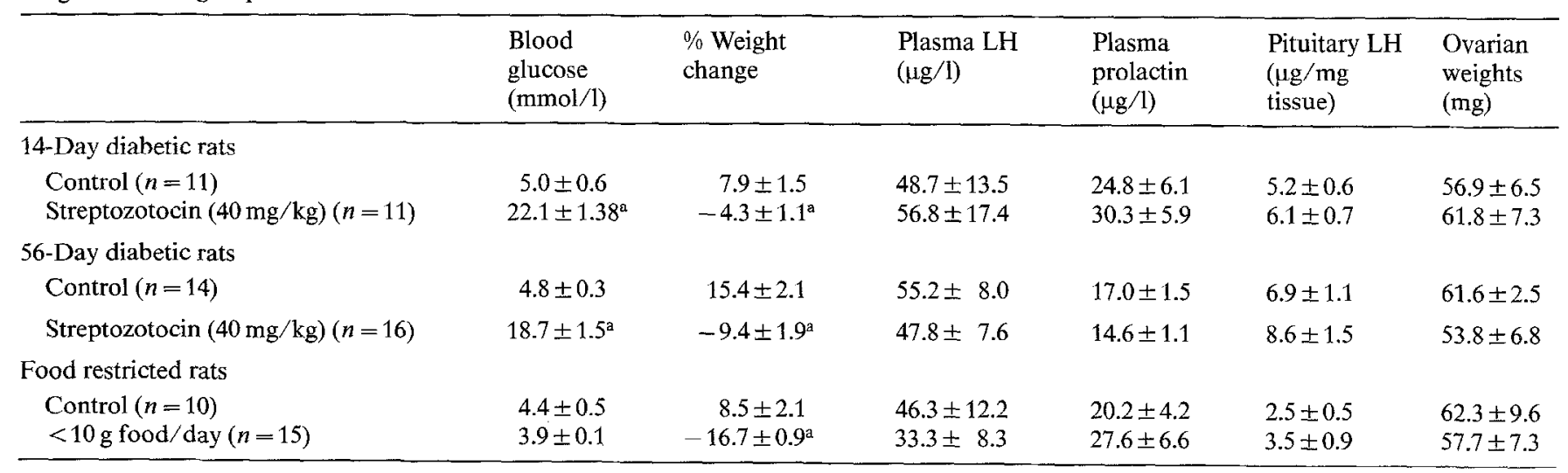

Values expressed as mean \pm SEM; the number of observations are given in parentheses. ${ }^{a} p<0.01$ significant difference compared with their paired controls (Student's t-test)
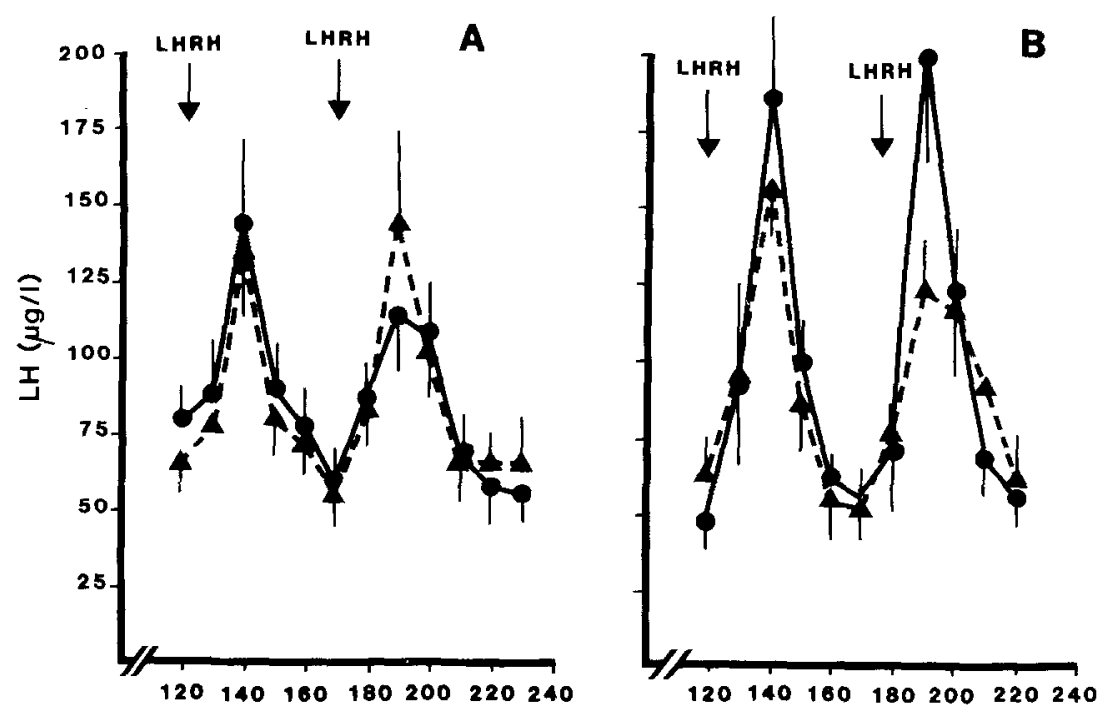

Fig. 2. Pituitary responsiveness to LHRH measured in vitro from pituitary glands of oestrous and dioestrous rats. A The responses measured from 11 rats treated with $\mathrm{STZ}(40 \mathrm{mg} / \mathrm{kg}) 56$ days prior to experimentation compared with eight vehicle-injected control rats. B The responses observed from cight rats placed on a food restricted diet 26 days before experimentation compared with eight unfasted controls. 0 : experimental group, $\Delta$ : control group

TIME (min)

\section{Experiment 2. Effect of chronic diabetes on ovarian} cyclicity and pituitary responsiveness to $\mathrm{LHRH}$

In these experiments animals were treated with STZ $(40 \mathrm{mg} / \mathrm{kg})$ only, the higher dose not being suitable for long term maintenance of uncontrolled diabetes in rats. In the first group of animals diabetes was induced 14 days before experimentation, while in another goup, diabetes was maintained for 56 days before investiga- tion (Table 3). There was no significant differences in circulating levels of LH or prolactin, pituitary LH content or ovarian weights between diabetic and control animals although the STZ treatment significantly raised blood glucose concentrations and reduced body weight in both 14 day and 56 day diabetic rats $(p<0.01)$.

In the 14-day diabetic group a state of constant dioestrous was induced in 10 of the 16 animals investigated. This acyclicity was observed $6.4 \pm 0.22$ days after 

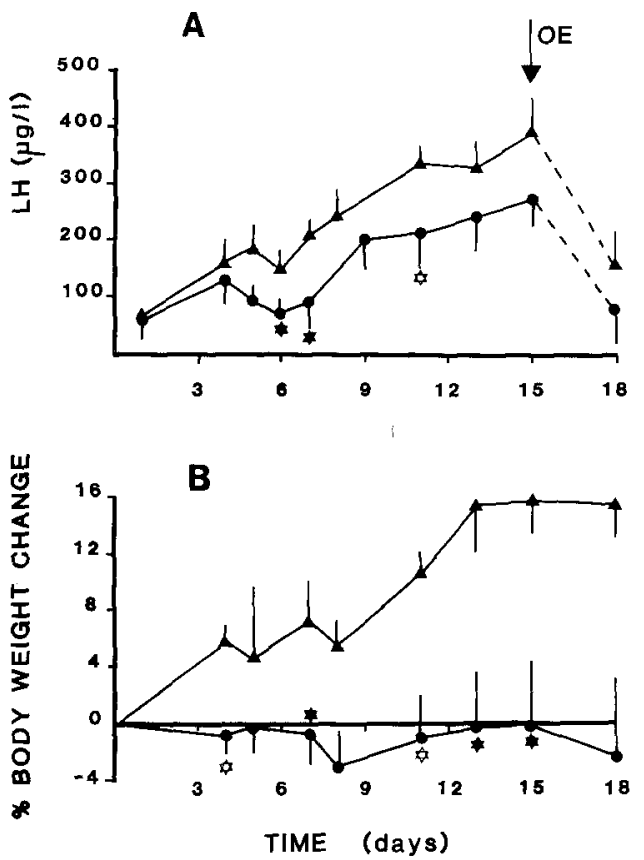

Fig. 3. Effects of STZ $(40 \mathrm{mg} / \mathrm{kg})$ treatment on the rise of $\mathbf{L H}$ secretion and body weight after ovariectomy in the rat. $:$ diabetic animals $(n=8) ; \Delta$ : vehicle treated control rats $(n=11)$. Oestrogen (OE, $80 \mu \mathrm{g} / \mathrm{kg}$ ) was administered on day 15 after ovariectomy and exerted a negative feedback effect on LH secretion. $* p<0.05$ and $p<0.01$ (Student's t-test)

drug treatment and the mean body weight loss was $6.4 \pm 1.3 \%$. Fifty-six days after drug-induced diabetes all treated animals were acyclic. There was no apparent change in pituitary responsiveness to LHRH between diabetic animals maintained for either 14 or 56 days and their respective controls, and the data for 56-day diabetic animals are shown in Figure 2. Control rats which were in proestrus on the day of experimentation were excluded from the analysis of these results due to elevated pituitary responsiveness, although data from dioestrous and oestrous animals have been pooled.

\section{Experiment 3. Effects of body weight loss on oestrous cyclicity and pituitary responsiveness to $L H R H$}

The mean body weight loss after 26 days on a food restricted diet was $16.73 \pm 0.93 \%$. Of the 15 animals investigated, six showed regular oestrous cycles throughout the course of the experiment, while the remaining nine displayed constant dioestrous smears after a mean period $10.8 \pm 1.1$ days on a food restricted diet. The onset of constant dioestrus occurred when the mean body weight loss was $11.2 \pm 0.6 \%$. There were no significant differences in plasma levels of LH and prolactin, pituitary LH content or ovarian weights between the food restricted animals and controls (Table 3 ). Similarly weight loss had no effect on in vitro pituitary LH responses to LHRH when compared with dioestrous controls (Fig. 2).

\section{Experiment 4. Effects of diabetes on steroid feedback action and pituitary responsiveness to $\mathrm{LHRH}$ in ovariectomized rats}

The $\mathrm{LH}$ rise after ovariectomy was attenuated in the rats treated with STZ $(40 \mathrm{mg} / \mathrm{kg})$ compared with the controls, although statistically significant differences $(p<$ 0.05 ) were only observed on day 3 of testing (Fig. 3). On day 15 , before the oestrogen administration, there were no significant differences in the LH concentrations between experimental and control groups, although experimental animals had significantly higher blood glucose levels $(24.08 \pm 2.68 \mathrm{mmol} / 1, p<0.001)$ compared with unfasted controls $(5.9 \pm 0.445 \mathrm{mmol} / \mathrm{l})$, but lower $(p<0.01)$ body weights (Fig. 3). Two out of the eight diabetic rats had ketonuria. Seventy-two hours after the oestrogen treatment (day 18), LH levels were reduced in all animals but the surge of $\mathrm{LH}$, induced $5 \mathrm{~h}$ after the progesterone treatment, was markedly attenuated in the diabetic compared with control rats (Fig. 4).

The results obtained from a second group of animals which were chronically ovariectomized three weeks before treatment with STZ $(40 \mathrm{mg} / \mathrm{kg}$ ) are shown in Table 4. Thirty days after drug treatment there was a significant reduction in circulating levels of LH $(p<$ 0.001 ), but there was no difference in the pituitary responsiveness to LHRH when tested in vitro.

\section{Discussion}

STZ has a wide diabetogenic dose range from 40 to $120 \mathrm{mg} / \mathrm{kg}$, and this has led to the development of different forms of STZ-induced diabetes [12]. In endocrine experiments, where STZ has been used to induce diabetes in rats, the drug is typically given as a single intraperitoneal injection at doses ranging from 60 to $120 \mathrm{mg}$ / $\mathrm{kg}$. In these experiments a lower dose of the drug has been used $(40 \mathrm{mg} / \mathrm{kg})$ and this dose induced hyperglycaemia reliably without ketonuria; these animals could be maintained for long periods. However, with the higher dose of STZ $(80 \mathrm{mg} / \mathrm{kg})$, ketonuria was frequently detected and the animals could not be maintained for periods longer than a week. In this case non-specific toxic effects of the drug must be considered.

A comparison of the high and low dose STZ-induced diabetes showed that after 3 days only the high dose of the drug had any marked effects on the control of gonadotrophin secretion. In this group of animals ovulation was inhibited, the increased pituitary responsiveness to LHRH, which occurs on proestrus [11], was absent, and there was a significant reduction in plasma prolactin. In animals treated with STZ $(40 \mathrm{mg} / \mathrm{kg})$ there was no observed self-priming effects of LHRH on pituitary responsiveness [13] although other parameters of gonadotrophin control appeared normal; ovulation was not inhibited.

In contrast, normal ovarian cyclicity was abolished in chronic (14 or 56 day) diabetic rats treated with STZ 


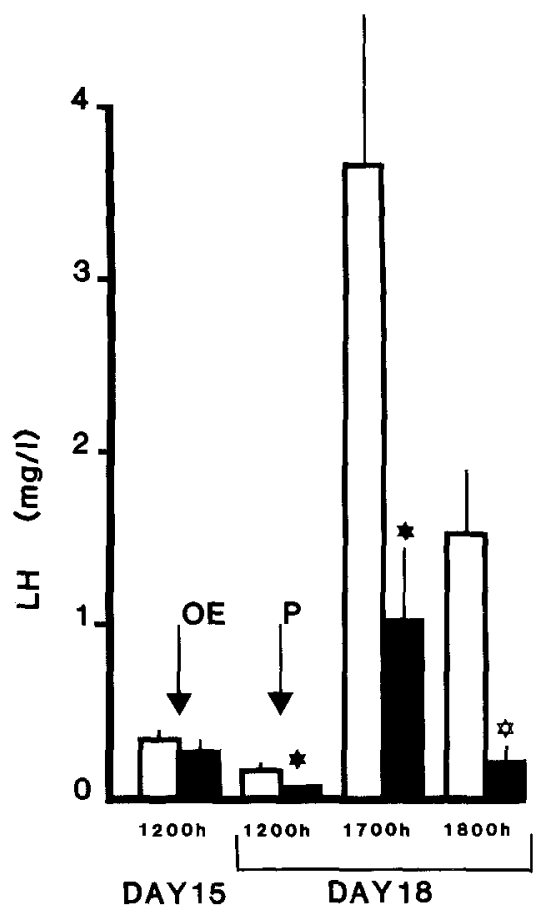

Fig.4. Feedback effects of exogenous steroids in ovariectomized rats treated with STZ $(40 \mathrm{mg} / \mathrm{kg})$. Oestrogen $(\mathrm{OE}, 80 \mu \mathrm{g} / \mathrm{kg}$ ) was injected immediately after the first blood sample on day 15 after ovariectomy, and progesterone $(P, 10 \mathrm{mg} / \mathrm{kg}$ ) was given immediately after blood sampling at $12.00 \mathrm{~h}$ on day 18 after ovariectomy. $\square:$ control animals $(n=11), \square$ : diabetic rats $(n=8) . * p<0.02, \$ p<0.01$ (Student's t-test)

Table 4. Effects of STZ $(40 \mathrm{mg} / \mathrm{kg})$ administered to ovariectomized rats on body weight, blood glucose concentrations, plasma levels of LH and prolactin, and in vitro pituitary LH responses to LHRH 30 days after drug treatment

\begin{tabular}{ccc}
\hline & $\begin{array}{l}\text { Streptozotocin- } \\
\text { treated rats }\end{array}$ & Control rats \\
\hline $\begin{array}{c}\text { Blood glucose } \\
\text { (mmol/l) }\end{array}$ & $16.8 \pm 1.3^{\mathrm{a}}$ & $4.3 \pm 0.5$ \\
$\begin{array}{c}\text { \% body weight } \\
\text { change }\end{array}$ & $-11.1 \pm 2.1^{\mathrm{a}}$ & $(12)$ \\
Plasma LH & $(14)$ & $(10.4 \pm 1.6$ \\
$(\mu \mathrm{g} / \mathrm{l})$ & $352 \pm 50^{\mathrm{a}}$ & $641 \pm 52$ \\
Plasma prolactin & $(14)$ & $(12)$ \\
$(\mu \mathrm{g} / \mathrm{l})$ & $19.3 \pm 3.5$ & $17.2 \pm 2.2$ \\
Pituitary LH response & $(14)$ & $(12)$ \\
to LHRH & $258 \pm 45$ & $278 \pm 56$ \\
\hline
\end{tabular}

We expressed as mean \pm SEM; the number of observations are given in parentheses. The pituitary LH response gives the peak increases in LH secretion of perifused pituitary glands after 5-min pulses of LHRH $\left(10 \mathrm{ng} / \mathrm{ml}\right.$ ). ${ }^{a} p<0.01$ compared with controls (Student's t-test)

( $40 \mathrm{mg} / \mathrm{kg}$ ), while basal secretion rates of $\mathrm{LH}$ and prolactin, and the pituitary gonadotrophin response to LHRH, were similar to control animals. In the 14-day diabetic animals, in which daily vaginal smears were monitored, a state of constant dioestrous was induced after a period of 1 week and the mean body weight loss of acyclic animals was $6.4 \pm 1.3 \%$. A similar state of constant dioestrus was observed in those rats placed on a food-restricted diet but in this case the acyclicity occurred when the mean body weight was reduced by $11.2 \pm 0.6 \%$ after a mean period of $10.8 \pm 1.1$ days. Both these figures are significantly different from those recorded from the diabetic animals $(p<0.02)$, suggesting that body weight loss alone cannot account for ovulatory failure observed in diabetic rats. These results agree with those reported by Katyama et al. [14] who showed that the pre-ovulatory LH surge, and hence ovulation, was not inhibited in food-restricted rats which had lost $8.5 \%$ body weight, while the frequency of ovulation was reduced in diabetic rats with a mean body weight loss of only $3.9 \%$.

Short-term diabetes (2-6 days) induced with alloxan [2] or STZ [3] can inhibit the ovulatory response to pregnant mare's serum gonadotrophin in immature rats, and this has been associated with a reduced pituitary responsiveness to LHRH and an inhibition of the pre-ovulatory LH surge [14]. More recently a study on adult rats also reported that STZ $(65 \mathrm{mg} / \mathrm{kg})$, administered 4 days before experimentation, could inhibit or delay the pre-ovulatory LH surge, even though preliminary studies showed that the oestrous cycles were predominantly regular during a 6-7 day period after drug treatment. In contrast the in vivo pituitary response to LHRH $(500 \mathrm{ng} / \mathrm{kg})$ and self-priming effects of the releasing hormone, were not significantly different in diabetic compared with controls animals [14]. However, the mean peak responses were lower in the experimental animals, and the relatively high dose of LHRH used may have over-ridden more subtle changes in pituitary responsiveness.

Overall, these and other studies show that diabetes is associated with a loss of the pre-ovulatory LH signal and that the onset of this effect is dependent upon the dose of drug used to induce the diabetic state. A reduction in pituitary responsiveness to LHRH could explain this inhibition in some animal models although Greig and Weisz [15] estimated that only $10-15 \%$ of the spontaneous peak LH levels were required for ovulation, implying that a dramatic reduction in LHRH secretion or pituitary sensitivity to LHRH is required to inhibit ovulation. A reduction of ovarian responsiveness to gonadotrophin or impaired steroidogenesis could cause the ovulatory failure in diabetes $[3,16]$, although in the immature alloxan-treated rat ovarian oestrogen secretion appeared normal [4]. Thus, to eliminate either primary or secondary effects of diabetes on ovarian steroidogenesis the effects of exogenous steroids in the ovariectomized rat model were investigated.

The expected rise in $\mathrm{LH}$ secretion after ovariectomy [17] and the positive and negative feedback effects of exogenous steroids [13] were observed in the vehicle treated control animals, while in the diabetic rats the $\mathrm{LH}$ response to steroid withdrawal, and the positivefeedback effect of progesterone in oestrogen-primed 
animals was attenuated. These data provide direct evidence that diabetes impairs the feedback effects of steroids, and a hypothalamic rather than a pituitary site of action is indicated since streptozotocin treatment did not reduce pituitary responsiveness to LHRH in longterm ovariectomized rats.

The number of oestradiol receptors in the hypothalamus and pituitary gland is decreased in diabetes [19], and this may account for the reduced sensitivity to the feedback effects of steroids. Alternatively diabetes may have a direct action on the LHRH synthesis/release mechanisms, and this would also be manifest by an apparent failure to respond to the feedback effects of steroids. Although in this and another study [4] diabetes did not alter the total hypothalamic content of LHRH, this does not necessarily indicate normal LHRH secretion. Indeed, the observation that ovulation in alloxantreated rats can be restored by repeated injections of LHRH on proestrus [4] is strong evidence of a hypothalamic failure. Furthermore, a hypothalamic defect in diabetes is also implied by the abnormal morphology of hypothalamic nuclei and the median eminence in diabetic Chinese hamsters [20] and in streptozotocin-treated male rats [21].

In summary these and other data suggest that the ovulatory failure observed in diabetes results, at least in part, from an impaired steroid feedback action on the hypothalamus and a failure of the hypothalamic LHRH signal. Since LHRH regulates its own receptors on the pituitary gonadotrophs [5], a reduction in LHRH secretion could explain the reported reduction of pituitary responsiveness in immature rats, although studies on adult rats do not support this observation [12]. On the other hand, steroid feedback mechanisms also exert a direct effect on the pituitary [11], and these are important for increasing the sensitivity of the gonadotrophs to LHRH, prior to the pre-ovulatory LH surge. Thus the attenuated steroid feedback action and consequent loss of ovulation in diabetes may result in both hypothalamic and pituitary defects in the control of gonadotrophin secretion. However, the available evidence is more strongly in favour of the hypothalamus being the primary site a which diabetes mellitus reduces fertility.

Acknowledgements. We are grateful to the National Hormone and Pituitary Program for radioimmunoassay materials and to Dr. H. M. Fraser for the gift of the LHRH antiserum.

\section{References}

1. Bergquist N (1954) The gonadal function in female diabetics. Acta Endocrinol (Suppl) (Copenh) 19:3-13

2. Kirchick HJ, Keyes PL, Frye BE (1978) Etiology of anovulation in the immature alloxan-diabetic rat treated with pregnant mare's serum gonadotophin: absence of the preovulatory luteinising hormone surge. Endocrinology 102: 1867-1873

3. Vomachka MS, Johnson DC (1982) Ovulation, ovarian 17-hydroxylase activity and serum concentration on luteinizing hormone, oestradiol and progesterone in immature rats with diabetes mellitus induced by streptozotocin. Proc Soc Exp Biol Med 171-215

4. Kirchick HJ, Keyes PL, Frye BE (1979) An explanation for anovulation in immature alloxondiabetic rats treated with pregnant mare's serum gonadotrophin: reduced pituitary responses to gonadotrophin-releasing hormone. Endocrinology 105: 1343-1349

5. Clayton RN, Catt KJ (1981) Gonadotrophinreleasing hormone receptors: characterization, physiological regulation and relationship to reproductive function. Endocrine Rev 2: 186-209

6. Molitch ME, Hou SH (1983) Neuroendocrine alterations in systemic disease. Clin Endocrinol Metab 12: 825-851

7. Whitehead SA, Pennington JM, Carter DA (1982) Dynamic changes in pituitary responses to luteinizing hormone releasing hormone after ovariectomy in the rat. J Endocrinol 93: 75-81

8. Niswender GD, Midgley AR Jr, Monroe SE, Reichert LG Jr (1968) Radioimmunoassay for rat luteinizing hormone with antiovine LH serum and ovine LH- ${ }^{131}$ I. Proc Soc Exp Biol Med 128: $807-811$

9. Niswender GD, Chen CL, Midgley AR, Meites J, Ellis S (1969) Radioimmunoassay for rat prolactin. Proc Soc Exp Biol Med 130: 793-797

10. Jeffcoate SL, Fraser HM, Holland DT, Gunn A (1974) Radioimmunoassay of luteinizing hormone-releasing hormone (LHRH) serum from man, sheep and rat. Acta Endocrinol (Copnh) 75: $625-635$

11. Kendall MG, Stuart A (1968) Analysis of variance in the linear mode. In: Advanced theory of statistics, $2 \mathrm{edn}$, Vol 3. Griffin, London, pp 1-56

12. Junod A, Lambert AE, Orci L, Pictel R, Gonet AE, Reynold AE (1967) Studies of the diabetogenic action of streptozotocin. Proc Soc Exp Biol Med 126: 201-205

13. Fink $\mathrm{G}$ (1979) Feedback action of target hormones on hypothalamus and pituitary with special reference to gonadal steroids. Ann Rev Physiol 41: 571-580

14. Katayama S, Brownscheidle CM, Wooten V, Lee JB, Shimaoka K (1984) Absent or delayed preovulatory luteinizing hormone surge in experimental diabetes mellitus. Diabetes 38: 324-327

15. Greig F, Weisz J (1973) Preovulatory levels of luteinizing hormone, the critical period and ovulation in rats. $\mathbf{J}$ Endocrinol 57: 235-245

16. Barbibi RL (1983) Effects of insulin on steroidogenesis in cultured ovarian theca. Fertil Steril 40: 237-241

17. Tapper CM, Naftolin F, Brown-Grant K (1972) Influence of the reproductive state at the time of operations on the early response to ovariectomy in the rat. J Endocrinol 53:47-57

18. Calligaris L, Astrada JJ, Taleisnik S (1968) Stimulating and inhibiting effects of progesterone on the release of luteinizing hormone. Acta Endocrinol 59: 177-185

19. Gentry RT, Glade GN, Blaustein JD (1977) Binding of ${ }^{3} \mathrm{H}$-estradiol by brain cell nuclei and female rat sexual behaviour: inhibition by experimental diabetes. Brain Res 130: 135-146

20. Garris DR, Smith C, Davis D, Diani AR, Gerritsen GC (1982) Morphometric evaluation of the hypothalamic-ovarian axis of the ketonuric, diabetic Chinese hamster: relationship to the reproductive cycle. Diabetologia 23: 275-279

21. Rossi GL, Bestetti G (1981) Morphological changes in the hypothalamic-hypophyseal-gonadal axis of male rats after twelve months of streptozotocin-induced diabetes mellitus. Diabetologia 21: 476-481

Received: 28 August 1984

and in revised form: 17 April 1985

Dr. S. A. Whitehead

Department of Physiology

St. George's Hospital Medical School

Cranmer Terrace

London SW17 ORE

UK 